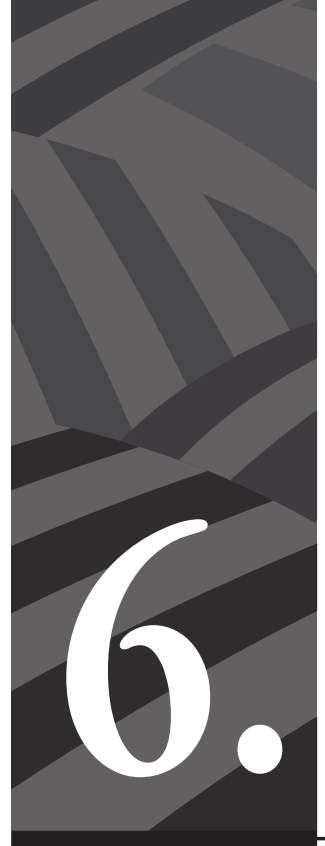

Experiencias internacionales de procesos de paz y de transición hacia la democracia: La incidencia del movimiento sindical 


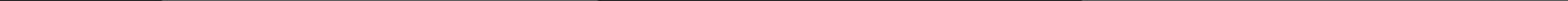




\section{Experiencias internacionales de procesos de paz y de transición hacia la democracia: La incidencia del movimiento sindical ${ }^{1}$}

Por Kjeld Jakobsen²

\section{Introducción}

4 ste texto tiene como objetivo discutir el papel del movimiento sindical en la superación de los conflictos, violencia y autoritarismo político en diferentes momentos históricos. El objetivo es verificar el nivel de su incidencia en los procesos de paz y normalización democrática de los países estudiados. Del mismo modo, se busca dar cuenta de la formulación de acuerdos de recuperación de derechos de los trabajadores -por lo general violados durante los regímenes autoritarios-, así como del fortalecimiento de sus mecanismos de representación. Finalmente, se busca también verificar la participación sindical en el establecimiento de culturas de paz.

Esta información, resultado de diversas experiencias nacionales, podrá servir de insumo para el debate del movimiento sindical en Colombia en el momento de la implementación de los Acuerdos de Paz; del

Artículo recibido en septiembre de 2106

Artículo aprobado en noviembre de 2016.

2 Trabaja como consultor sobre relaciones internacionales, cooperación para el desarrollo y asuntos sindicales y como consultor de la Confederación Sindical de las Américas (CSA). Ha trabajado extensivamente con sindicatos de Brasil y fue miembro de la Junta Nacional Ejecutivo de la CUT Brasil entre 1991 y 2003. 
mismo modo en que resultara de utilidad para el proceso de negociación entre el Gobierno nacional y el ELN. La sociedad colombiana no debe permanecer ajena a este proceso y se espera que los sindicatos y las centrales sindicales de Colombia aprovechen la oportunidad que se abrió con las negociaciones en Cuba, así como se abren actualmente con las negociaciones en Ecuador. Estas oportunidades son claves para exigir la formación de una nueva cultura política en la cual se respeten la democracia, la justicia social y las libertades sindicales.

Los conflictos que analizamos se caracterizan, por un lado, por tener múltiples orígenes y, por el otro, por ser procesos de paz y/o de redemocratización que ocurrieron bajo la salvaguardia del neoliberalismo introducido a nivel internacional desde finales de los años setenta. Es fundamental aquí señalar que esta dominancia corriente política, la neoliberal, tiene como uno de sus fundamentos el desmantelamiento de las conquistas sociales del período posguerra de la Segunda Guerra Mundial. Este es el caso del grupo de países que se analizarán, y entre ellos se registran los conflictos derivados de intentos de superar las hegemonías y estructuras agrarias arcaicas apoyadas por el imperialismo estadounidense en varios países de Centro América.

En este interés de delimitación geografía, vale señalar que otro proceso está representado por las experiencias de superación de las dictaduras y las transiciones a la democracia en el Cono Sur. Por ejemplo, Perú fue incluido debido a que el gobierno autocrático de Alberto Fujimori estuvo en vigor durante diez años con un terrible record de violaciones al DDHH, cometidas en la presencia de un gobierno democrático formal. Por último, se analiza la transición del régimen de apartheid en Sudáfrica hacia una situación de normalidad democrática y de inclusión de la población negra, mayoritaria en el país, en la definición de sus destinos y con acceso a sus derechos civiles fundamentales. También es relevante señalar que en Guatemala, tras el golpe de Estado que en 1954 derrocó al presidente reformista Jacobo Arbenz hasta el Acuerdo de Paz en 1996, se identifican los extremos de la violencia con la ocurrencia de un genocidio. 
Los conflictos de estas regiones, en conjunto, causaron la pérdida de cientos de miles de vidas, desperdicio de enormes sumas de recursos, además de producir graves violaciones de los Derechos Humanos básicos por muchos años. Aun así, debe anotarse que, por un lado, en la mayoría de las situaciones se lograron acuerdos de paz duraderos y la reconciliación entre las partes, pero, por otro lado, estos se dieron sin cambiar la mayoría de las situaciones económicas y sociales.

El movimiento sindical fue un actor importante de resistencia ante la opresión que caracterizó a estos conflictos, pero no siempre logró destacarse en los momentos definitivos que marcaron el rumbo de los países en términos de normalización democrática. En la mayoría de los casos, el movimiento sindical fue excluido de las mesas de negociación, así, los intereses que prevalecieron fueron los de la élite y sus partidos políticos. Además, durante el conflicto no había relaciones laborales normales y el papel que los sindicatos cumplieron fue más político y militante, y a menudo a favor de una de las partes, lo que tornaba difícil volver a un papel normal después de establecida la paz.

Sin embargo, también es necesario verificar si lo acordado fue respetado y si el movimiento sindical tuvo un rol o no que debía ser garantizado. Así que la primera lección importante para el sindicalismo colombiano es la necesidad de ganar un espacio en el debate nacional si se quiere influir en la normalización de la vida del país y contribuir para convertir la superación del conflicto en el fundamento de un desarrollo más justo y equitativo de Colombia, además del establecimiento de una cultura de paz.

\section{Las guerrillas de América Central y los acuerdos de paz}

Aquí trataremos tres situaciones con procesos similares: Nicaragua, El Salvador y Guatemala. Estos casos sirvieron al presidente de los Estados Unidos Ronald Reagan para justificar, con la “Teoría del domino”, 
su intervención militar en contra del "avance del comunismo" en Centro América ${ }^{3}$.

\section{Nicaragua}

El Frente Sandinista de Liberación Nacional (FSLN) operó en Nicaragua durante 17 años. Su accionar se hizo desde la clandestinidad para vencer a través de una insurrección popular que reunió guerrilleros, campesinos, sectores burgueses y los trabajadores organizados en las zonas urbanas. La corrupción y la violencia de la dinastía Somoza que gobernó el país por cuarenta y cinco años escandalizaron al mundo, incluido el público americano.

Las perturbaciones comenzaron cuando en 1976 la dictadura fue la causante del robó de los recursos de la ayuda humanitaria internacional para las víctimas del terremoto que destruyó gran parte de Managua. Asimismo, en 1979 fueron de nuevo la corrupción y la violencia los factores detrás de la ejecución a sangre fría de un periodista estadounidense a manos de un soldado nicaragüense; hecho que fue trasmitido por la prensa.

Se estima que la cifra de muertos para hacer frente a Somoza, fue de aproximadamente 50 mil y, como señala Zimmermann (2020), el país fue devastado económicamente por la guerra y el robo de bienes que Somoza y sus aliados se llevaron cuando huyeron del país. Después de la victoria de la revolución, el país fue gobernado por una junta integrada por representantes del FSLN y las clases altas que se habían opuesto al régimen de Somoza. Un ejemplo de ellos fue Violeta Chamorro, viuda de Pedro Chamorro, periodista y propietario del diario opositor La Prensa asesinado en 1978 por orden del dictador.

3 Esta teoría suponía que los países de América Central caerían bajo la órbita comunista, uno tras otro debido a las acciones de las guerrillas izquierdistas. Después de Nicaragua, lo siguiente sería El Salvador y luego Guatemala. 
El programa de gobierno de los sandinistas desarrolló una política que fusionó las actividades económicas del sector privado con la expropiación de la propiedad y la tierra de la familia Somoza y sus cómplices, esto con el fin de desarrollar experiencias de autogestión y reforma agraria. Además, adoptaron una serie de programas sociales para elevar los niveles de salud de la población y erradicar el analfabetismo. Políticamente crearon milicias y Consejos de Defensa de la Revolución, además de la policía y el ejército sandinista. Aunque, los sandinistas no implementaron un estricto régimen socialista, la derecha dejó de cooperar con el régimen y sus representantes renunciaron a la junta de gobierno.

Con la inauguración del mandato de Reagan en Estados Unidos, el nuevo gobierno de Nicaragua tuvo que enfrentar a la hostilidad de este país cuyo gobierno comenzó a financiar la organización de un poderoso grupo contrarrevolucionario con sede en Honduras y compuesto principalmente por exmiembros de la Guardia Nacional somozista que huyeran del país después de la revolución. Después de su reelección en 1984, Ronald Reagan promulgó un bloqueo comercial a Nicaragua y el embargo de sus bienes nacionales en el extranjero. El gobierno nicaragüense convocó a una elección presidencial y legislativa para el mismo año, donde los sandinistas fueron los ganadores con $67 \%$ de los votos y una nueva Constitución entró en vigor en 1987. A partir de los Acuerdos de Esquipulas, el Gobierno sandinista levantó la censura de prensa, creó una Comisión de Reconciliación Nacional, permitió el regreso de algunos opositores exiliados y concedería amnistía a los contrarios que estuvieran dispuestos a deponer las armas.

La economía estaba en una situación de grave crisis a causa de las consecuencias de la guerra, y, en segundo lugar, debido a la falta de preparación de los nuevos gestores para garantizar la productividad necesaria de las empresas. Además a esto se le sumaba, como señala Zimmermann (2002), un sabotaje de los empresarios y las acciones de los "contras". 
Al inicio del proceso electoral, adelantado para 1990, los sandinistas presentaron la candidatura de Daniel Ortega a la reelección, y catorce partidos de la oposición se unieron a la Unión Nacional de Oposición (UNO) y presentaron la candidatura de Violeta Chamorro, exmiembro de la Junta de Gobierno que triunfó por 55\% a $41 \%$ sobre los sandinistas. Los sandinistas entregaron el gobierno tras la firma de un Protocolo de Transición que exigía el respeto a la Constitución en vigor, a las instituciones y a los logros sociales de la revolución, así como la continuidad del desarme de los "contras". La presidenta se comprometió a asumir personalmente el Ministerio de la Defensa y mantener a Humberto Ortega en el mando del ejército. Entre 1987 y 1990 los sandinistas propusieron una serie de acuerdos a los Estados Unidos, así como lo hicieron con la oposición interna, la finalidad de esta acción política era aliviar la presión que asfixiaba la economía y las condiciones sociales de los nicaragüenses; por ello cuando perdieron las elecciones negociaron el mantenimiento de los principales logros de la revolución.

Muchos sindicatos jugarán un papel importante en los levantamientos urbanos, especialmente en los últimos años con el enfrentamiento al gobierno somozista. Después de la victoria sandinista en 1979 hubo muchos incentivos para la organización sindical y diversas organizaciones, como la Asociación de Trabajadores del Campo (ATC), la Central Sandinista de Trabajadores (CST) y el Frente Nacional del Trabajo (FNT), las cuales abarcan las diversas organizaciones sociales y sindicales sandinistas. Estos intentos se ampliaron en gran medida durante la década de 1980. Debido a ello, Violeta Chamorro, cuando asumió el poder en 1990, tuvo que enfrentarse a una fuerte huelga del sector público y cumplir con parte de sus demandas a pesar de haber intentado derrotarla. Cuando su gobierno inició el proceso de privatización de las empresas estatales de todo tipo concedió $25 \%$ de la propiedad a los respectivos sindicatos. 


\section{El Salvador}

Debido a unas elecciones que tuvieron un trato ilegal, en 1977 el general Carlos Humberto Romero se convirtió en presidente. Este hecho provocó protestas en el territorio nacional que fueron reprimidas con gran violencia, lo cual dejó como resultado un saldo de siete mil muertes. Una de las primeras acciones de este gobierno fue situar en la ilegalidad a los partidos de la oposición. Esta situación dio aliento a los grupos guerrilleros que coordinaron acciones entre sí, además de promover la unión en 1980 de cinco grupos guerrilleros que quisieron sumarse a las filas del Frente de Liberación Nacional Farabundo Martí (FMLN).

Romero fue derrocado en 1979 y sustituido por una junta civil y militar compuesta por oficiales más jóvenes que él, así como miembros de la socialdemocracia y la democracia cristiana. Sin embargo, la junta no podía manejar la represión de la oposición y las acciones de los escuadrones de la muerte (grupos paramilitares). Estos lograron tanta impunidad que en 1980 asesinaron al arzobispo de San Salvador, Oscar Romero, en plena luz del día mientras celebraba la misa. Los miembros civiles renunciaron y fueron reemplazados por un sector conservador de la Democracia Cristiana liderado por Napoleón Duarte. Al año siguiente, la FMLN lanzó una ofensiva general y amplió sus operaciones a todas las regiones del país, y formó una alianza con el Frente Democrático Revolucionario (FDR), que incluía parte de la Unión Nacional de Oposición (UNO), así el FMLN-FDR comenzó a recibir reconocimiento internacional como una fuerza representante del pueblo salvadoreño.

Sin embargo, el entonces nuevo presidente de Estados Unidos Ronald Reagan manejó el conflicto en El Salvador como un asunto de seguridad nacional. Su estrategia era fortalecer las fuerzas armadas salvadoreñas con fondos, armas y entrenamiento. Estas acciones le permitían promover la participación directa de asesores militares estadounidenses en el conflicto, en combinación con la política institucional, la cual abrió espacio para la participación de las fuerzas políticas moderadas del país. 
Pese a la apertura política que parecía favorecer la diferencia, en 1982 se celebraron elecciones para una Asamblea Constituyente, la cual, sin embargo, resultó presidida por el mayor Roberto D’Aubuisson, líder de la Alianza Republicana Nacionalista (ARENA) y mentor del asesinato del Monseñor Oscar Romero.

En las elecciones presidenciales de 1984, boicoteadas por el FMLNFDR, Estados Unidos apoyó al demócrata cristiano Napoleón Duarte, quien fue el ganador con el $47 \%$ de los votos mientras que el $51 \%$ de la población se abstuvo de votar. A pesar de la presión de los militares de extrema derecha, su elección fue reconocida por el alto mando de las fuerzas armadas y en el mismo año se produjo el primer contacto entre representantes del gobierno y de la guerrilla. Estos contactos se reanudaron en 1987 dentro de un nuevo marco de paz regional, y se dio gracias a la firma de los Acuerdos de Esquipulas I y II hecha por los gobiernos de América Central. Estos acuerdos preveían el final de la ayuda externa a los grupos insurgentes armados existentes en cada país, promocionaban el diálogo interno con la mediación de la Iglesia Católica, daban amnistía a aquellos dispuestos a deponer las armas y manifestaran compromiso de participar en la vida política. Sin embargo, Duarte intentó profundizar las negociaciones respaldadas por Estados Unidos con el FMLN-FDR entre 1987 y 1989 pero no resultó debido a la fuerte resistencia por parte de la extrema derecha y de los militares.

En 1989 el frente guerrillero propuso un nuevo boicot a las elecciones presidenciales en 1989, pero el FDR rompió la alianza y lanzó un candidato, Guillermo Ungo, quien se posicionó en tercer lugar mientras que el ganador fue Alfredo Cristiani, de la Alianza Republicana Nacionalista (Arena). El FMLN lanzó una ofensiva importante ese año y llegó a ocupar varios distritos de la capital. Ante este fenómeno, la respuesta del Gobierno fue bombardear varias zonas densamente pobladas y promover una serie de ataques. Una bomba explotó en la sede de la Federación Nacional Sindical de los Trabajadores Salvadoreños (Fenastras) y asesi- 
nó a nueve dirigentes sindicales, entre ellos la Secretaria General, Febe Velásquez. La sede del Comité de Madres y Familiares de Detenidos, Desaparecidos y Asesinados Políticos de El Salvador (Comadres) fue dinamitada, y dos semanas más tarde seis jesuitas y dos empleados de la Universidad Centroamericana José Simeón Cañas (UCA) fueron asesinados por un grupo de militares de un batallón de élite entrenado por el ejército estadounidense. Estos hechos fueron condenados por la comunidad internacional y casi se pone en riesgo la cooperación de Estados Unidos con El Salvador.

El diálogo de paz se reanudó en México en 1991 y el Comité Permanente del Debate Nacional (CPDN) organizó una movilización de más de diez mil personas para exigir la firma de un acuerdo de paz y la promoción de la reforma de la Constitución. Vale anotar que el CPDN fue fundado en 1988 y estaba compuesto por setenta y un entidades de la sociedad civil salvadoreña, incluyendo la Unidad Nacional de Trabajadores Salvadoreños (UNTS), además, contaba con el apoyo de la Iglesia Católica.

El primer acuerdo de El Salvador se firmó, en su primera fase, el 27 de abril de 1991, y los diálogos se reanudaron en noviembre del mismo año bajo supervisión de la ONU. Esto derivó en una firma de acuerdos definitivos el 1 de enero de 1992 en New York, y se basó en el compromiso de finalizar todas las hostilidades entre febrero y octubre de ese año. El balance de los doce años de período de la guerra civil, desde la unificación del FMLN y la firma de los acuerdos finales de paz, fue de 75 mil muertos, ocho mil desaparecidos y un millón de refugiados.

Según anotan Montgomery y Wade (2002), los principales compromisos acordados fueron:

1. Reducción de las fuerzas armadas a la mitad, cambio de su estructura y formación, así como la limitación de sus funciones a la defensa de la soberanía y de la integridad nacional. 
2. Disolución de los servicios de inteligencia.

3. La distribución de tierras a los excombatientes de ambos lados y la prestación de asistencia técnica y financiera a los colonos.

4. Creación de un foro económico tripartito para discutir el modelo de desarrollo del país y normalizar las relaciones de trabajo.

5. La creación de una Policía Nacional Civil para reemplazar la Policía Nacional, la Guardia Nacional y la Policía de Hacienda, esto con el fin de dar cabida, en parte, a los excombatientes del Frente Farabundo Martí para la Liberación Nacional (FMLN).

6. Creación de una Comisión de la Verdad para investigar las violaciones al DDHH cometidas durante la guerra civil.

7. Transformación de la FMLN en partido político legalmente reconocido.

Los últimos miembros de la guerrilla entregaron sus armas el 15 de febrero de 1993 y la Comisión de la Verdad verificó que el entonces ministro de Defensa, René Emilio Ponce, fuera el autor intelectual del asesinato de los jesuitas en 1989 lo que provocó su renuncia. La Comisión también encontró que el $95 \%$ de los casos de violación de los Derechos Humanos eran de responsabilidad militar, de los escuadrones de la muerte vinculados a ellos y del Estado en general. Fue recomendado el despido de 102 jefes militares y la pérdida de los derechos políticos de algunos exlíderes guerrilleros. El presidente Cristiani propuso por las mismas fechas una ley de amnistía que logró aprobar, con lo cual evitó castigo a ambos partes.

Para el caso de El Salvador, el saldo de los efectos del acuerdo es positivo con salvedades. En primer lugar, se trata de un acuerdo duradero hasta hoy, sin reanudación de las hostilidades, a pesar de los muy precarios indicadores sociales y de la alta criminalidad, lo cual permaneció 
en vigor en los años posteriores a la guerra. Pero, pese a dichos indicadores, se estableció un consenso en el país: no aceptar más asesinatos por razones políticas.

Por otra parte, la concertada distribución de la tierra no se produjo en el tamaño y velocidad esperados. En 1994, del total de 37 mil guerrilleros y miembros del ejército desmovilizado, solo 12 mil -un tercio de lo previsto- recibieron sus tierras; lo que derivó en que muchos excombatientes insurgentes terminaran integrados a bandas criminales. Aunque la amnistía general evitó el castigo, en la práctica, jefes militares involucrados en la violación de los Derechos Humanos fueran retirados de sus cargos. Otro aspecto, a señalar se dio en relación al Foro Económico, el cual fue boicoteado rápidamente por los empresarios, y la UNTS informó que el Gobierno estaba violando los acuerdos y había empezado una campaña contra las organizaciones sociales.

Aunque los sindicatos tuvieron un papel político importante y reconocido por la sociedad salvadoreña durante el conflicto, cuando los enfrentamientos bélicos terminaron estos perdieron representación en la base de trabajadores. La UNTS, a pesar de toda la represión, era muy militante, además de caracterizarse por ser uno de los principales voceros de las denuncias de violación de los Derechos Humanos y sindicales. Cuando la guerra terminó, los sindicatos tuvieron mucha dificultad para reemplazar el activismo político del período de la guerra por un rol más relevante en los conflictos de las relaciones laborales y entre el capital y el trabajo. Por lo tanto, como rastrearon Montgomery y Wade, (2002), la densidad sindical rápidamente se redujo a 6\% promedio en el país.

La FMLN, tras actuar como partido político, tuvo el 25,5\% de los votos en las primeras elecciones presidenciales en 1994. Como movimiento político legal amplió su espacio en las elecciones municipales en 1997, cuando eligió alcaldes de la capital y otras ciudades importantes y finalmente alcanzó la presidencia del país en 2009. 


\section{Guatemala}

La reacción de la izquierda armada de Guatemala, ante la concentración de la tierra y sus consecuencias, surgió inicialmente en la década de 1960 con la fundación de las Fuerzas Armadas Rebeldes (FAR). A la par, surgieron gobiernos dirigidos por miembros de las fuerzas armadas, o por civiles con protección militar, quienes fueron escogidos por medio de elecciones ilegales. A este se añadirían, ya en los años setenta, los grupos guerrilleros del Ejército Guerrillero de los Pobres (EGP) y la Organización del Pueblo en Armas (OPA). En 1982 hay una integración de todos, además del Partido Guatemalteco del Trabajo (PGT), y forman la Unidad Revolucionaria Nacional Guatemalteca (URNG).

Varios grupos de Derechos Humanos estiman que la represión militar contra la izquierda entre 1954 y 1982 habría causado cerca de 80 mil víctimas. En 1982, hubo un golpe de Estado que puso el general Efraín Ríos Montt como presidente y en el primer año de su gobierno 15 mil guatemaltecos fueron asesinados, 70 mil buscaron refugio en los países vecinos y 500 mil buscaron refugio en las montañas del país. Cientos de aldeas rurales fueron devastadas y aumentó el número de "aldeas modelo" donde los campesinos fueron alojados por la fuerza y obligados a producir para la exportación y no para sus propias necesidades.

En 1983 se produjo un nuevo golpe de Estado que depuso a Ríos Montt y, tras el acto, el general Oscar Mejía Víctore prometió un rápido retorno a la democracia. Este retorno se daría a partir de la convocatoria de una Asamblea Nacional Constituyente en 1984, que a su vez aprobó el derecho de huelga de los trabajadores de las empresas estatales, autorizó el regreso de algunos exiliados y convocó a las elecciones presidenciales de 1985. Aun así, dichas elecciones fueron boicoteadas por la URNG, aunque dieron la victoria al demócrata cristiano Vinicio Cerezo, quien ordenó la suspensión total y definitiva de las actividades de la policía secreta. 
En 1984, después de más de veinte años de conflicto armado, los representantes del Gobierno y de la URNG se reunieron por primera vez para iniciar la negociación de un acuerdo de paz. La Comisión Nacional de Reconciliación (CNR), creada según lo propuesto por los acuerdos de Esquipulas, tomó un papel de liderazgo junto con la ONU para acercar a las partes. En la continuación de las negociaciones se estableció una agenda y en 1990 se firmó un acuerdo básico. Sin embargo, un acuerdo definitivo solo se viabilizó seis años después.

El contenido de este acuerdo se refiere, básicamente, a cuestiones tales como la democratización del país, los Derechos Humanos , el fortalecimiento del poder civil y la función del ejército en una sociedad democrática, identidad y derechos de los pueblos originarios. También alude a la reforma constitucional y del sistema electoral, a aspectos socioeconómicos, la situación agraria y el reasentamiento de las poblaciones rurales dispersas por la lucha armada y la reintegración política de la guerrilla. También se creó una Comisión de la Verdad y se acordó no “individualizar” a los responsables por violaciones de Derechos Humanos.

El balance de este acuerdo en Guatemala merece muchas advertencias, aunque debe reconocerse que el terror político terminó. Sin embargo, tras los acuerdos ocurrieron asesinatos selectivos de dirigentes sindicales y de los movimientos sociales hasta la actualidad. Durante las últimas elecciones de 2011, fueron asesinados al menos 30 activistas. Aunque la guerra en Guatemala duró 27 años, mucho más tiempo que en los países vecinos, se hizo más evidente en la década de 1980, antes de la caída del muro y del fin de la Revolución Sandinista, que una victoria de la guerrilla ya no era posible; ni siquiera lo era llegar a un acuerdo que conllevara cambios políticos y sociales contundentes. Así pues, en la década de los ochenta, la guerrilla se limitó a luchar para garantizar el respeto de los Derechos Humanos y del Estado de Derecho. Esto, como anota Grandin (2002), permitió que los militares y la élite del país utilizaran las negociaciones y los acuerdos alcanzados para consolidar su poder y control sobre el país. 
La estimación final del número de víctimas en 1996 fue de 200 mil muertos, 50 mil desaparecidos, cerca de 200 masacres y millones de refugiados. La mayoría de las víctimas (75\%) fueron las comunidades indígenas, sobre quienes cayó un genocidio como producto de las violaciones de los Derechos Humanos en Guatemala. Hay denuncias muy concretas sobre algunas de las atrocidades cometidas por el ejército, escuadrones de la muerte y otros grupos paramilitares como las Patrullas de Autodefensa Civil (PAC). Por ejemplo, en 1993 encontraron los restos de 177 personas, entre ellas mujeres y niños, víctimas de la masacre de Río Negro perpetrado por el ejército en 1982. En el mismo año, el gobierno acabó con los registros de los ciudadanos que consideraba peligroso para la seguridad nacional, pero las actas de los responsables de violaciones de Derechos Humanos desaparecieron también. En 1995, el general Ríos Montt, que había sido elegido diputado y presidente del Congreso, perdió su inmunidad parlamentaria y fue juzgado por el Tribunal Supremo por una serie de delitos que no estaban directamente vinculados con el genocidio; sin embargo, no tuvo mayores consecuencias. Esto sirve para anotar que la impunidad es una marca importante de la política en Guatemala. Aun así, en 1999 varias organizaciones guatemaltecas de Derechos Humanos reivindicaron al gobierno por investigar los crímenes cometidos entre 1983 y 1985 sobre la base de un informe interno con 183 nombres de personas desaparecidas.

El reasentamiento de las poblaciones desplazadas por la guerra también fue extremadamente lento y limitado. La inserción de la guerrilla en la política también fue difícil y muchos que participaron de la lucha armada militan en diferentes partidos de izquierda hoy. Debe decirse que pese a la incursión política de la insurgencia dentro del marco legal, esta solo presentó una candidatura presidencial en 2011, pero apenas alcanzaran el $5 \%$ de los votos.

El movimiento sindical en Guatemala también fue reprimido durante la fase de la dictadura de la década de los ochenta, además de tener que hacer frente al ajuste estructural neoliberal desde 1994. Sin embargo, organizaciones como la Unión Sindical de Trabajadores de Guatemala 
(Unsitragua) jugaron un papel importante para contribuir a las protestas por las violaciones de los Derechos Humanos . Pero su incidencia en el proceso de paz fue pequeño, quizás se debió a las mismas razones que afectan su funcionamiento hoy en día, y se debe a su organización fragmentada, lo que deriva en una densidad sindical no superior al $2 \%$ en el país. Sin embargo, las organizaciones campesinas, indígenas y ONG eran más activos durante el período comprendido entre la firma del primer acuerdo y el último. Por ejemplo, en 1994 hubo una marcha de 5 mil indígenas reclamando la extinción de la Patrullas de Autodefensa Civil (PAC).

\section{Transiciones de dictaduras para regímenes democráticos}

En este apartado del texto se discuten dos situaciones diferentes de transiciones de dictaduras hacia regímenes democráticos. Son los casos de cuatro dictaduras militares del Cono Sur: Argentina, Brasil, Chile y Uruguay, y el caso de Perú que, en el período democrático, fue víctima de un gobierno autocrático que exhibió un terrible historial de corrupción y de violaciones de Derechos Humanos .

En Argentina, el primer gobierno de Juan Domingo Perón promovió un importante proceso de industrialización, implementó un robusto sistema de protección social, fortaleció la organización sindical, así como las confederaciones empresariales, y duró nueve años antes de ser derrocado en 1955 por un golpe militar. El peronismo fue un fenómeno político con mucha fuerza y trascendencia, pero, a pesar de su base inicial obrera y sindical, y de haber sido responsable por la creación de una legislación social importante, se dividió entre sectores de derecha e izquierda. Por ejemplo, Carlos Menem fue elegido presidente en 1989 por el Partido Justicialista (peronista) y, al tiempo, implementó uno de los gobiernos neoliberales más radicales de América Latina.

Cuando Perón fue depuesto en 1955 se exilió en España y regresa a territorio argentino dieciocho años después. Mientras tanto hubo una su- 
cesión de gobiernos elegidos democráticamente así como varios golpes milita res. A pesar de la proscripción del peronismo, los peronistas continuaron influyentes en la política nacional, así como en los sindicatos. En las elecciones de 1973, Héctor Cámpora, candidato del justicialismo, salió victorioso y su misión era preparar el regreso de Perón, que tuvo lugar dos meses después, cuando Cámpora renunció para causar la celebración de nuevas elecciones donde Perón fue elegido con el $63 \%$ de los votos. Para este gobierno, en su nuevo gobierno Perón tuvo a con su segunda esposa, María Estela Martínez, como vicepresidente, quien asumió un año después la presidencia tras la muerte de su marido.

En 1975, el ejército derrocó a la presidenta, suspendió todas las garantías constitucionales e implementó una feroz represión contra la izquierda a través de secuestros, torturas y asesinatos. Se estima que alrededor de 25 mil personas desaparecieron durante los ocho años que duró la dictadura. Los militares argentinos también introdujeron una atrocidad desconocida hasta entonces: el secuestro y entrega de los niños nacidos de encarceladas para adopción por miembros de las fuerzas armadas. Las embarazadas eran mantenidas con vida hasta dar a luz para solo después ser ejecutadas.

Durante los tres gobiernos militares que se sucedieron, Argentina fue, después de Chile, el nuevo laboratorio del monetarismo y del neoliberalismo en América del Sur. Los dictadores promovieron una política de liberalización de las importaciones que liquidó un tercio de la capacidad productiva del país, los salarios reales se redujeron a la mitad y se suprimieron una serie de beneficios sociales. Las economías regionales, en particular el sector agrario, se vieron terriblemente afectadas por las altas tasas de interés, la cual alentó una especulación financiera desenfrenada.

Estas medidas plantearon cuestiones internas a las que el tercer presidente de período, el general Leopoldo Galtieri, respondió con la invasión de las Islas Malvinas buscando generar la unidad cívica en el país. Pero 
los ingleses expulsaron a los argentinos de las islas después de cuarenta y cinco días de combates. Dos días después Galtieri renunció, hubo una purga parcial en la cumbre de las tres fuerzas armadas y las elecciones generales fueron convocadas para octubre de 1983, cuando Raúl Alfonsín, líder de la Unión Cívica Radical (UCR), fue elegido.

La primera casta que llegó con el nuevo gobierno civil dio en relación a la respuesta que había de darse por las graves violaciones al DDHH durante la dictadura, pues, vale anotar, Alfonsín ganó las elecciones como candidato de la legalidad y de la vida contra la arbitrariedad y la muerte. Durante el juicio de los nueve comandantes en jefe de la dictadura, una Comisión Nacional sobre la Desaparición de Personas (Conadep) expuso los horrores que tuvieron lugar bajo su determinación. La condena y el alcance de los cargos a otros oficiales de bajo rango llevaron a varias presiones en la esfera militar, lo que incluyo el acuartelamiento de algunos sectores. El gobierno llamó a una gran manifestación en defensa de la democracia, pero después de negociaciones del presidente con los militares se dio el retiro de algunos comandantes y la aprobación por el Congreso de la ley del "punto final”. Al año siguiente se dio la ley de "obediencia debida” para eximir a los militares involucrados en las violaciones de Derechos Humanos cometidas bajo órdenes superiores. El presidente que sucedió a Alfonsín fue Carlos Menem, quien promovió medidas institucionales adicionales para eximir a los militares involucrados en la "guerra sucia"; entre ellos promovió el indulto para los miembros de las fuerzas armadas y para los de grupos armados de izquierda que aún estaban arrestados.

Fue solo durante el gobierno de Néstor Kirchner, 2003-2007, que fueron derogadas estas medidas y varios militares aun vivos, incluidos los jefes de gobierno durante la dictadura, fueron encarcelados. Sin embargo, la continuación de las investigaciones sobre los desaparecidos y el destino de los bebés secuestrados, hoy en día adultos, continúa bajo iniciativas de organizaciones de la sociedad civil como las "Madres de la Plaza de Mayo" y las "Abuelas de la Plaza de Mayo”. 
Por su parte, el papel del movimiento obrero durante la dictadura y su rebasamiento fue ambiguo. Por un lado, hubo muchos dirigentes sindicales y delegados de base entre los desaparecidos debido a su militancia política y sindical. También hubo sindicatos que sufrieron intervenciones de las fuerzas armadas por ejercer sus actividades sindicales normales en defensa de los derechos de los trabajadores. Sin embargo, también hubo un importante sector de dirigentes de la Confederación General del Trabajo (CGT) que colaboraron con la dictadura a través del pacto sindical militar, e incluso hubo casos en que militantes fueron denunciados por dirigentes sindicales. En 2000, la Fitim suspendió la afiliación al sindicato de trabajadores metalúrgicos (Smata) después de que su presidente José Rodríguez se encarara de exponer a muchos trabajadores de Mercedes y Ford a la represión. Varios de ellos se encuentran entre los desaparecidos.

Cuando terminó la dictadura, la CGT se dividió en dos fracciones, luego vino una tercera disidencia a la izquierda auspiciada por la Asociación de Trabajadores del Estado (ATE), por la Confederación de Trabajadores de la Educación (Ctera), así como por algunos sindicatos de la industria; de esta tercera disidencia e fundó la Central de Trabajadores Argentinos (CTA). La participación de los sindicatos en la transición democrática se dio básicamente en la negociación con el gobierno de Alfonsín, la cual fue fundamental para aprobar la ley 23.551 que normalizó el funcionamiento de los sindicatos, la negociación colectiva y el regreso de la gestión de “obras sociales" - cuidado de la salud y la seguridad social- para las federaciones sindicales.

\section{Brasil}

En Brasil el gobierno de João Goulart fue derrocado por un golpe militar en 31 de marzo 1964, y la dictadura que siguió a este hecho fue de larga data: 21 años. Al principio hubo numerosas prisiones de comunistas y otros considerados subversivos por los militares, así como intervenciones en miles de sindicatos que tenían sus liderazgos destituidos 
debido a que muchas de las cabezas sindicales estaban en presión. Se suprimieron los partidos políticos que fueron reemplazados por dos partidos solamente, lo que empeoro la situación de la oposición. Cuando la izquierda armada urbana intensificó sus acciones a partir de 1968, ocurrió lo llamado el "golpe dentro del golpe”. Esto conllevó numerosas detenciones, suspensión del funcionamiento del Congreso, la pérdida del mandato de varios parlamentarios, suspensión del Habeas Corpus y el comienzo de una dura represión contra la izquierda con el aumento de torturas, asesinatos y desapariciones. Los diversos focos guerrilleros, en su mayoría urbanos, así como una iniciativa del Partido Comunista de Brasil (PC do B) en la región amazónica, fueron totalmente destrozados en poco tiempo por medio de graves violaciones al DDHH.

La primera crisis del petróleo encubrió el “milagro económico” que había generado el crecimiento del PIB brasileño de casi $12 \%$ por año entre 1970 y 1972. Después de una gran victoria electoral de la oposición en 1974, para llenar la mayoría de los escaños en el senado disputado -un tercio ese año-, los ideólogos del régimen militar comenzaron a diseñar un retorno a la normalidad democrática de forma "lenta, segura y gradual”. Así, unos años más tarde se quitó la censura previa de la prensa, y en 1979 se aprobó una amnistía para ambos lados, es decir para los militantes de izquierda y los agentes del Estado que reprimían, a la vez que se aprobó una ley que permitió la creación de nuevos partidos políticos.

Para las elecciones generales de 1982 se aprobó la elección directa de los gobernadores de los estados que había sido suprimida en 1966. La elección directa para el cargo presidencial solo se produjo en 1989. Si se toma 1974 como el inicio de la transición democrática brasileña, entonces esta duró 15 años. Cosa que resulta coherente con la tradición histórica del país de promover cambios suaves en las negociaciones “entre los de arriba”, es decir, los acuerdos realizados por las cúpulas de las elites nacionales. Sin embargo, en esta última transición democrática fue fundamental el movimiento obrero, especialmente los sindicatos 
que surgieron en los sectores económicos avanzados, resultantes del desarrollismo brasileño. Las primeras grandes huelgas que se llevaron a cabo produjeron negociaciones directas entre empleadores y trabajadores en el sector automóvil en el estado de São Paulo en 1978. Este movimiento se extendió a otros sectores económicos, como la petroquímica, refinación de petróleo, la electricidad, las telecomunicaciones e, incluso, sectores públicos tales como la educación y la salud.

Estas manifestaciones no se limitaron a las demandas económicas, por más necesarias que fueses, sino que también incluyeron la demanda por el fin de control estatal sobre la organización sindical, así como plantearon elecciones directas para presidente y la convocatoria de una Asamblea Nacional Constituyente. En 1980 se fundó el Partido de los Trabajadores (PT), lo cual se realizó a partir de una propuesta emitida por el movimiento sindical y que incluía personas que militaran contra la dictadura desde los años 1960 hasta los 1980. Durante los primeros años de la década del ochenta el sector sindical auténtico logró fundar la Central Única de los Trabajadores (CUT), que funcionó hasta 2008 de hecho, más no de derecho, ya que la legislación sindical en Brasil no preveía la existencia de centrales sindicales ${ }^{4}$.

El movimiento sindical brasileño nunca fue unitario por razones ideológicas. En la lucha contra la dictadura había diferentes puntos de vista sobre las prioridades en el campo de la izquierda y la omisión total de los sindicalistas oficialistas (amarillos), y muchos de ellos habían cooperado con los militares. Esta diferencia también se reveló en el momento de incidir en el trabajo de la Asamblea Constituyente completada en 1988. Esta no fue exclusiva, sino, más bien, una tarea asignada a los parlamentarios electos en 1986. Sin embargo, hay varios derechos laborales que se insertaron en la Constitución como la licencia de pater-

El gobierno del Presidente Lula aprobó una ley en 2008 que reconocía y legalizaba las centrales sindicales bajo ciertos criterios mínimos de representación. 
nidad, la licencia de maternidad ampliada a 120 días, la jornada laboral de seis horas para los trabajadores por turnos, entre otros. Más tarde, durante el enfrentamiento de las políticas neoliberales que se tornaron políticas de Estado entre 1990 y 2002, la división y la posición de las diferentes centrales.

En cuanto a la violación de los Derechos Humanos durante la dictadura, la CUT defendía el castigo de los torturadores, pero esta propuesta no resultaba muy atractiva. Más tarde, con el lanzamiento de un estudio muy detallado realizado por la iglesia católica a partir de los procesos judiciales de los presos políticos y testimonios personales de ex presos que sobrevivieron y que incriminaban militares y policías como autores de torturas, así como los informes de asesinatos y desapariciones, comenzó a formarse una opinión en la sociedad sobre la necesidad de tomar medidas con el fin de esclarecer lo sucedido. Así, varios grupos se organizaron para exigir iniciativas para descubrir la verdad sobre la dictadura. Un ejemplo de ello es la organización “Tortura Nunca Más” y otras en el área de los Derechos Humanos. La primera reacción provino del gobierno de Fernando Henrique Cardoso de proponer una indemnización a los afectados por la represión de la dictadura. Eso generó muchos casos individuales reclamando esta compensación, incluidos numerosos sindicalistas.

Durante el gobierno de Luiz Inácio Lula, varios abogados alegaron en el tribunal y trataron de llevar adelante la tesis de que los delitos de secuestro y desaparición son inalienables según la opinión de la Corte Interamericana de Derechos Humanos, pues son crímenes continuos. Algunos jueces de tribunales inferiores comprendieron las denuncias, pero otros se aferraban a la tesis de la amnistía mutua, la cual fue reafirmada por la Corte Suprema.

Veinticinco años después del fin de la dictadura, la presidenta Dilma Rousseff compuso una Comisión de la Verdad para investigar e informar sobre lo ocurrido en la represión política entre 1945 y 1988 en 
cuanto a las responsabilidades por las desapariciones políticas y otras violaciones de los Derechos Humanos ${ }^{5}$. Esta Comisión ya ha emitido su informe que concluyó que hubo más de 400 desapariciones forzadas y culpó a muchos agentes del Estado, incluidos los generales presidenciales. El movimiento sindical y la CUT participaron de este trabajo haciendo levantamiento de informaciones sobre la represión política en el sector laboral y la responsabilidad empresarial en aquel momento. Esto se hizo ya que el golpe de 1964 fue civil y militar, y muchos trabajadores fueron despedidos por su activismo político, a la vez que varios de ellos fueron arrestados en sus lugares de trabajo.

No hay duda, en el caso brasileño, que al menos el sector progresista del movimiento obrero tuvo un papel importante en la lucha contra la dictadura, así como en la construcción de una sociedad e instituciones democráticas en el período que culminó con la elección, por primera vez, de un trabajador para conducir el país en 2002.

\section{Chile}

Un marxista fue elegido como presidente de Chile en 1970: el 35\% de los votos, después de tres intentos anteriores, le dieron la presidencia a Salvador Allende, candidato del frente de izquierda Unidad Popular (UP), quien tres años después de posesionarse se suicidó para evitar ser detenido durante el golpe militar organizado por el general Augusto Pinochet.

La dictadura fue responsable de muchos asesinatos y desapariciones poco después del golpe de Estado. Las atrocidades cometidas en el Estadio Nacional de Santiago fueron unos de los hechos más atroces de esa dictadura, pues allí fueron recluidos los miembros y simpatizantes

Estas fechas fueron aprobados para reducir la oposición de los militares a la instalación de la Comisión, pero, en la práctica, las investigaciones estaban en eventos entre 1964 y 1985. 
de la UP para ser interrogados, torturados y ejecutados a menudo; a ese mismo nivel estaban los campos de concentración creados para encarcelarlos. También hay que señalar que la Central Unitaria de Trabajadores (CUT) y los partidos políticos fueran proscritos. Puede decirse que, con conciencia de la gravedad de estos hechos, en 1978 el gobierno decretó una amnistía para los "actos delictuosos” durante el golpe.

La política económica adoptada fue el monetarismo/neoliberalismo con el asesoramiento directo de Milton Friedman y la Escuela de Economía de Chicago con resultados desastrosos desde el punto de vista de la concentración del ingreso y el crecimiento de los exiliados económicos; aunque unos años más tarde se produjo un importante retorno al crecimiento económico. En 1981 el régimen impulsó una nueva Constitución de continuidad del sistema con apoyo de más del $60 \%$ de los votos, aunque no hay mayor seguridad en relación a los números reales del resultado de este referéndum, ya que las listas electorales databan de antes del golpe de Estado. Poco después comenzó un ciclo recesivo en 1983, lo cual devino en que el $55 \%$ de las familias pasaron a vivir por debajo del umbral de la pobreza; con este motivo se realizaron protestas que tuvieron a la cabeza de la Coordinación Nacional Sindical (CNS) y el Comando Nacional de Trabajadores (CNT). Estas organizaciones no eran reconocidas por el Gobierno, pues se había creado una ley laboral que legalizaba solo los sindicatos de base que podrían formarse a partir de la voluntad de al menos 14 trabajadores. Así, se establecieron decenas de sindicatos en una misma empresa, pero estos no poseían ningún poder real de representación.

En 1984 la Iglesia Católica tomó la iniciativa de promover un diálogo político entre la oposición, la Alianza Democrática (AD), una coalición de partidos de centro-derecha liderados por los demócratas cristianos y, por el lado del gobierno, el ministerio del interior. El diálogo fracasó rápidamente y la Iglesia también se alejó del Gobierno y comenzó a presentar denuncias sobre la violación de los Derechos Humanos. La izquierda se agrupó en el Movimiento Democrático Popular (MDP) y 
defendía todas las formas de lucha contra la dictadura. El intento de unificar a la oposición en 1985 chocó con la cuestión de la lucha armada que ya era parte de la estrategia del Partido Comunista de Chile $(\mathrm{PCCH})$, esta lucha se dio a través del Frente Patriótico Manuel Rodríguez (FPMR) y del Movimiento de Acción Popular Unitaria (Mapu).

En 1987, el régimen hizo posible que los partidos políticos, menos los de izquierda, fueran legalizados y al año siguiente propuso un nuevo referéndum con el fin de ampliar el mandato de Pinochet por ocho años más. Si no se hubiese aceptado este referéndum habrían sucedido elecciones un año después. En preparación para el referéndum, el Gobierno permitió la realización de campaña pública y el amplio frente de oposición implementó una publicidad moderna y alegre que apuntaba a un futuro mejor en caso de ganar el "No"; como en efecto lo hizo por aproximadamente el $56 \%$ al $44 \%$ de los votos. El Gobierno aceptó el resultado, porque en este momento solo sobrevivían dictaduras militares en Chile y Paraguay, y la presión internacional era muy fuerte.

Las elecciones presidenciales y parlamentarias fueron convocadas para el año siguiente sobre la base de un acuerdo negociado entre los militares y la oposición, acuerdo que mantuvo la mayor parte de las políticas implementadas por el régimen en el campo económico y social. La reducción del período presidencial a cuatro años relajó la prohibición de los partidos de izquierda, pero se creó la figura del senador vitalicio con inmunidad para dar cabida a los miembros de la junta militar y otros aliados del régimen militar; además de la introducción de un sistema electoral que favoreció a la derecha. Pinochet, mantuvo inicialmente su cargo como jefe del ejército y después asumió el cargo de senador.

El presidente electo fue Patricio Aylwin, demócrata cristiano, candidato por la Concertación Democrática. Él asumió el cargo en 1990 y una de las primeras medidas adoptadas fue nombrar una Comisión de la Verdad y la Reconciliación para investigar violaciones al DDHH durante 
la dictadura de Pinochet. La Comisión dio a conocer detalles de lo que ocurrió durante el régimen militar y llegó a la conclusión de que hubo al menos 2.229 desaparecidos que luego fueron considerados muertos. Al revelar esta información, el nuevo presidente se disculpó en nombre del Estado y anunció que el proceso de investigación continuaría a través de los tribunales. Sin embargo, tanto las fuerzas armadas y de la Corte Suprema de Justicia negaron la validez del informe. Sin embargo, en 1995 los militares Pedro Espinoza y Manuel Contreras, ex jefe de la policía secreta (Dina), fueron condenados a prisión por el asesinato de Orlando Letelier, ex canciller de Allende; asesinato que se cometió en Washington en 1976. Más tarde, otros militares condenados cumplieron sus sentencias en un club construido especialmente para ellos, donde no pasaban ningún tipo de sufrimiento o restricción. Este privilegio se revocó solamente durante el mandato del presidente Sebastián Piñera, irónicamente un político de derecha, pues bajo su mandato aquellos fueron trasladados a cárceles ordinarias.

Otro paso importante para llevar a los responsables de violaciones de Derechos Humanos ante la justicia fue la detención de Pinochet en Inglaterra a petición del juez español Baltazar Garzón, orden que se emitió por el asesinato de ciudadanos españoles durante la dictadura. A pesar de que causó cierta conmoción y manifestaciones masivas nacionalistas a favor y en contra de la prisión, el episodio también sirvió para arrojar luz sobre la corrupción que se produjo durante el régimen militar, en particular por la familia del general.

El papel del movimiento sindical fue importante en la organización de manifestaciones y protestas durante la dictadura, así como en la campaña por el “No” en el año 1988. Antes del golpe la CUT era una organización muy fuerte e influyente en la izquierda, y recobró vida después de la dictadura cuando el CNS y la CNT se fusionaron para refundarla. Aunque su accionar no tuvo la misma fuerza que antes debido al nuevo sistema sindical y las leyes heredadas de la dictadura, las cuales están en vigor hasta hoy. Además, la dirección de la central 
llegó a estar compuesto de acuerdo con el peso de los diferentes partidos políticos que integran la Concertación Democrática, principalmente los demócratas cristianos y socialistas, y los militantes del Partido Comunista. En varios momentos las decisiones fueron tomadas a partir de los puntos de vista partidistas de estos frentes. Ante esta situación, los sindicatos no participaron directamente en las negociaciones de la transición chilena, pero sus partidos sí. Sin embargo, algunos sectores sindicales como los mineros de cobre y funcionarios públicos, como los maestros, han conservado la capacidad de movilizar.

\section{Uruguay}

Entre los países del cono sur se encuentra también Uruguay, el cual desarrolló una economía y Estado de bienestar social muy relevante a principios del siglo XX, hasta el punto de llevar al país a ser conocido como la Suiza Suramericana. Sin embargo, la falta de reinversión de la ganancia, principalmente por los ganaderos, causó una recesión industrial en la década de 1950 la cual nunca se revirtió. En la década siguiente la situación económica empeoró, y cuando el presidente Jorge Pacheco Areco en 1968 congeló los salarios y trató de reprimir a los sindicatos, la Convención Nacional de Trabajadores (CNT), junto con los estudiantes, se enfrentó a esta política.

Al mismo tiempo, el Movimiento de Liberación Nacional (MLN), más conocido como Tupamaros, promovió una serie de acciones armadas de impacto nacional, y en 1971 se fundó la coalición de izquierda Frente Amplio. Esta se presentó con un programa de gobierno progresista, y con el general retirado Liber Seregni como su candidato en las elecciones presidenciales celebradas ese año. Sin embargo, el ganador fue el “colorado” y ruralista Juan María Bordaberry, aunque el otro partido de derecha en Uruguay, el Nacional o "blanco”, denunció fraude en esas elecciones. Los Tupamaros fueron desmantelados por el ejército a principios del gobierno de Bordaberry mediante el uso sistemático de prisiones y tortura. 
En 1973 el presidente, en alianza con las fuerzas armadas uruguayas, dio un golpe de Estado civil/militar. El Congreso se cerró, se prohibieron los partidos políticos y los sindicatos, el Gobierno adoptó la doctrina de la seguridad nacional y personalidades del liderazgo civil comenzaron a desaparecer. La CNT convocó una huelga general contra el golpe de Estado, la cual duró dos semanas. Dos trabajadores murieron, cientos fueran detenidos y miles fueron despedidos. Las detenciones y torturas comenzaron a generalizarse, y se estima que durante los once años de la dictadura un tercio de la población llegó a ser detenida para interrogación por alguna razón política. La política económica adoptada se parecía mucho al laboratorio neoliberal en Chile. El ingreso se concentró y los salarios se redujeran en un $50 \%$ con respecto al valor anterior a 1973.

A comienzos de la década del ochenta, la dictadura intentó institucionalizar el sistema a través de un referéndum, pero fue derrotada y los generales tuvieron que preparar un cronograma de retorno a la normalidad democrática, aunque gradual y lentamente. En 1983 los militares empezaron negociaciones con los partidos conocidos como blanco y colorado, pero excluyeron al Frente Amplio, que todavía tenía muchos líderes en la cárcel, e incluyeron al presidente Liber Seregni y a otros en el exilio. Debe decirse que estas negociaciones se rompieron.

En el mismo año se formó la Plenaria Intersindical de Trabajadores (PIT) y en la celebración del 1 de mayo se reivindicó la liberación de los presos políticos; y a principios de 1984 el PIT convocó una huelga general de 24 horas. En la celebración del 1 de mayo de ese año se anunció la creación de una única central de trabajadores, el PIT-CNT. Poco después, el diálogo civil y militar se reanudó y esta vez con la participación del Frente Amplio alcanzó el "Pacto del Club Naval”. Aquí se abordaron cinco temas principales y se ajustaron detalles como la fecha de la elección presidencial. Los temas centrales fueron: la liberación gradual de 800 presos políticos, la derogación de algunos actos institucionales, la derogación de las proscripciones, la libertad 
de prensa y de finalización del juicio de civiles hecho por militares. Los exiliados regresaron pero a los presidentes del partido blanco y del Frente Amplio se les restringió la participación en las elecciones presidenciales que tuvieron lugar en noviembre de 1984. El ganador fue el candidato colorado, Julio María Sanguinetti. Este llevó adelante el programa económico neoliberal inaugurado por los militares, aunque desarrolló una política exterior que pretendía romper el aislamiento de la dictadura de la época; también incluyó la restauración de las relaciones diplomáticas con Cuba y Nicaragua.

En 1986, Sanguinetti obtuvo $75 \%$ de los votos en el Congreso para aprobar una amnistía a los militares acusados de violar los Derechos Humanos; esta amnistía se conoció como la Ley de Caducidad. En 1989 hubo un referéndum sobre la permanencia de esta ley donde el PIT-CNT hizo campaña por su derogación, pero el $56 \%$ de los votantes optó por mantenerla. Más tarde, bajo la presión de los familiares de desaparecidos políticos y de las organizaciones de derechos humanos, el presidente Jorge Batlle creó una Comisión de la Verdad en el año 2000 para determinar la situación y destino de las personas declaradas desaparecidos. En este comité participó José D’Elia, histórico dirigente sindical de Uruguay. La comisión investigó 228 casos de presuntas desapariciones y 83 de ellas fueron confirmadas, 80 parcialmente confirmadas y 56 descartadas. Sin embargo, la mayoría de desapariciones de uruguayos ocurrió en Argentina debido a la colaboración que existía en el área de represión política entre las dictaduras de Argentina, Bolivia, Brasil, Chile, Paraguay y Uruguay, que se conoció como la Operación Cóndor.

La comisión fue restablecida en 2003 y alcanzó casi las mismas conclusiones de antes. El Congreso uruguayo aprobó una ley en 2011 que permite castigar a los agentes estatales por delitos de lesa humanidad cometidos entre 1973 y 1985, lo que impidió efectivamente la prescripción de determinados delitos. Antes de esta ley hubo el juicio y condena a los principales dirigentes de la dictadura, Bordaberry y el general 
Gregorio Álvarez, pero no todos los jueces uruguayos tenían la misma comprensión que llevó a estas convicciones.

En los procesos de resistencia a la implantación de la dictadura, la presión política por el final de la misma, en la transición a la democracia y el debate sobre la violación de los Derechos Humanos, el sindicalismo uruguayo fue uno de los actores más activos en América Latina; aunque el PIT-CNT no participó directamente de las negociaciones del Club Na val. Sin embargo, su capacidad de organización y representatividad le aseguró un papel clave en las transformaciones que incluso permitió que el Frente Amplio ocupara el gobierno de Uruguay desde 2005.

\section{Perú}

Víctor Haya de la Torre, pensador y político de Perú, fue el fundador y líder del Partido de la Alianza Popular Revolucionaria Americana (Apra), que ideológicamente mezcla anticapitalismo, nacionalismo y antiimperialismo. Después de su fundación en 1923 se mantuvo durante muchas décadas como el partido político más popular y sólido en el Perú, pero a pesar de varias victorias electorales, la derecha y los militares nunca le permitieron gobernar. Fue solo en 1985 cuando Alan García fue elegido presidente por el Apra.

En la década de 1960, algunos disidentes del movimiento, y otros sectores de la izquierda revolucionaria, intentaron desarrollar una lucha guerrillera que no obtuvo al final el éxito. En 1968, un grupo de militares encabezado por el general Juan Velasco Alvarado derrocó al presidente Fernando Belaunde Terry, pero en lugar de iniciar una dictadura militar tradicional de la represión a la izquierda, y de alineación con el anticomunismo y la doctrina de la seguridad nacional de los EE.UU., implementó una serie de medidas para promover el desarrollo de la economía nacional. En ese sentido, impulsó la reforma agraria y la participación de los trabajadores en la gestión empresarial, creó un sector de empresas de propiedad social, expropió y entregó algunos 
órganos de prensa para sectores sociales organizados y desarrolló una política exterior independiente y no alineada.

Enfermo y físicamente frágil, Velasco Alvarado fue depuesto por su primer ministro, el general Francisco Morales Bermúdez, quien, presionado por el FMI y la oligarquía local con ganas de recuperar el poder, derogó muchas de las medidas anteriores y convocó elecciones para una Asamblea Constituyente en 1978; la finalidad era entregar los problemas a los políticos civiles. En la elección presidencial de 1980 el elegido fue Belaunde Terry que había sido despedido por Alvarado, y que llevó adelante una política económica desastrosa de conformidad con las directrices del FMI. El mismo año se puso en marcha la guerrilla maoísta del Partido Comunista del Perú - Sendero Luminoso (PCP-SL) y en 1984 este fue reforzado por la entrada en escena del Movimiento Revolucionario Túpac Amaru (MRTA).

En 1985, durante la crisis de la deuda externa, Alan García fue elegido presidente y fue sustituido cuatro años más tarde por el hasta entonces desconocido Alberto Fujimori. El populismo autoritario, pero neoliberal, se estableció en Perú con su posesión en 1990. Ante la oposición que tenía mayoría parlamentaria comenzó a gobernar por decreto y en 1992 dio un golpe de Estado con apoyo militar. Suspendió las actividades parlamentarias, desestimó a los jueces de la Corte Suprema y aprobó el ajuste estructural proporcionado por el Consenso de Washington como una guía para la economía. Gracias a las medidas económicas adoptadas con el apoyo del FMI logró que el Gobierno de Estados Unidos también lo apoyara. El apoyo interno superaba al $80 \%$ de la población debido al desgaste de las instituciones antes mencionadas.

Cambio 90, el partido de Fujimori, obtuvo en 1992 la mayoría de los votos para el "Congreso Constituyente Democrático", esto se dio debido a que los partidos tradicionales boicotearon las elecciones. Ese mismo año, mientras que el líder del PCP-SL, Abimael Guzmán, fue detenido, la popularidad del presidente se disparaba lo que le garantizó la reelec- 
ción en 1995. Dos años después Fujimori sustituyó a los magistrados del Tribunal Constitucional que habían declarado que una nueva reelección sería ilegal y en 2000 fue elegido por tercera vez por el partido Perú 2000.

Sin embargo, ese año se levantó controversia interna y externa sobre su derecho a afianzarse en el poder, pues al parecer había evidencia de fraude electoral. Poco después se dio a conocer un video que muestra a Fujimori y a su jefe de seguridad, Vladimiro Montesinos, sobornando a un parlamentario para unirse al partido del entonces presidente. Eso dio lugar a una serie de manifestaciones populares en contra del Gobierno y provocó la renuncia del presidente durante una reunión de APEC en Japón, así como de su asistente. El mandatario ya no tenía la mayoría en el Congreso y este no aceptó la renuncia y promulgó un juicio político sobre la base de "fracaso moral" de actuar como presidente.

A Fujimori le sucedió en forma interina el tercer vicepresidente del Congreso, Valentín Paniagua, mientras aquel permaneció en autoexilio en Japón durante cinco años. Cundo trató de regresar al país, alojándose inicialmente en Chile, fue detenido y extraditado para ser juzgado en el Perú. Entre 2007 y 2009 pasó por cuatro juzgados diferentes: se le acusaba de abuso de autoridad, invasión ilegal de domicilio, envío ilegal de fondos públicos, graves violaciones de los DD.HH y, además, por la responsabilidad en las masacres de Barrio Alto y La Cantuta ${ }^{6}$, así como el secuestro y asesinato de un periodista y un empresario después del golpe de 1992. El cuarto juzgado fue por escucha ilegal de teléfono y espionaje, soborno de congresistas y la compra ilegal de un canal de televisión. Su pena mayor, como anota Burt (2009), fue de 25 años en el tercer fallo, el máximo permitido por la ley peruana, además de pago de multas e indemnización a las víctimas.

6 En el Barrio Alto, el grupo Colina asaltó una casa y mató a 15 personas, entre ellas un niño de ocho años y en la Universidad de La Cantuta secuestró e hizo desaparecer a nueve estudiantes y un profesor. 
El récord negativo de diez años de gobierno de Fujimori es serio, ya que sucedió en un régimen formalmente democrático, aunque manipulado para que pudiera elegirse por tres veces. El manejo, así como el golpe de Estado de 1992 y la destitución de los jueces de la Corte Constitucional, fue la creación de un grupo paramilitar para su propio servicio, el Grupo Colina, que también actuó como escuadrón de la muerte contra personas consideradas subversivas. A este escuadrón se le unió el Servicio de Inteligencia Nacional (SIN), el cual estaba subordinado directamente a la presidencia y era utilizado para espiar e intimidar a los miembros de la oposición, así como el control de las instituciones peruanas, incluidos los medios. En 1995 se hizo indultó a los militares y policías condenados por violaciones de los Derechos Humanos en la lucha contra la guerrilla desde 1980, que incluía a miembros del Grupo Colina. También creó la figura de los “jueces sin rostro” que permanecieron en el anonimato durante los ensayos que justificaban como preservación de su seguridad personal. Estos jueces condenaron a más de dos mil personas entre 1992 y 1995. Cuando Fujimori dejó el cargo aún había unos 900 prisioneros. Este Gobierno también practicó intensa corrupción para beneficio personal y para mantenerse en el poder, incluyendo a los legisladores sobornados y otros personajes que le podían resultar de utilidad. Se estima que la corrupción entre 1990 y 2000 costó al Perú entre US\$ 1,5 a 4,0 mil millones de dólares.

El gobierno interino estableció una Comisión de la Verdad en el año 2001 con un mandato amplio para investigar las responsabilidades de los guerrilleros y agentes del Estado en lo relacionado a las violaciones de los Derechos Humanos en el Perú sucedidas entre 1980 y 2000. Cuando el presidente elegido en 2002 Alejandro Toledo asumió la presidencia extendió el número de miembros del comité para doce representantes y su nombre cambió para Comisión de la Verdad y Reconciliación (CVR). El informe final fue entregado en 2003 con los siguientes resultados: entre 1980 y 2000 murieron 69 mil personas víctimas de los conflictos y 15 mil personas fueron víctimas de desaparición forzada. El PCP-SL 
tuvo la responsabilidad del destino de 54\% de las víctimas, el 37\% fue responsabilidad de agentes de Estado, 2\% fue responsabilidad del MRTA y no fue posible determinar la responsabilidad de un $7 \%$ de las víctimas. Tres cuartas partes de las víctimas eran campesinos y la mayoría de ellos solo hablaban quechua u otra lengua indígena. Esta cifra es relevante para el análisis ya que en Perú solo el 16\% de la población no tiene el español como su primera lengua. Por lo tanto, al igual que ocurrió en el caso de Guatemala, Perú tiene en su historia un caso de genocidio.

Las principales recomendaciones de la CVR fueron:

- El Estado promoverá las reparaciones individuales y colectivas a las víctimas y sus familias.

- El Estado promoverá las reformas estructurales en su funcionamiento, especialmente en las fuerzas armadas, la policía y el poder judicial.

- El poder judicial debe abrir procesos en relación con los 47 más graves casos de violaciones de derechos humanos ${ }^{7}$.

- No aprobar amnistías o indultos que impidan la búsqueda de la verdad y la justicia.

Las recomendaciones de la CVR se inspiraron en gran parte por la jurisprudencia de la Corte Interamericana de Derechos Humanos, pero fue solo en 2006 que cuatro policías fueron condenados a 16 años de prisión por la desaparición de un estudiante. Según el coordinador de la CVR, Salomón Lerner, "la verdad no se conoce de forma automática y no conduce automáticamente a la reconciliación. Tiene que haber una mediación para lograr la reconciliación entre la verdad que no puede ser una condición suficiente, aunque es necesario, y la justicia condi-

La Procuraduría de Defensa del Pueblo añadió otros 12 casos a los 47 recomendados por la CVR. 
ción necesaria para la reconciliación” (Burt, 2009). Esta lógica supone que la mediación sería una combinación de reparación con acciones legales contra los responsables de violaciones.

El movimiento sindical fue una de las víctimas de la era Fujimori en materia de Derechos Humanos. Varios dirigentes sindicales se encuentran entre los desaparecidos y el más conocido es el del secretario general de la Confederación General de Trabajadores del Perú (CGTP), Pedro Huilca, secuestrado y asesinado por el Grupo Colina en 1992 por su oposición al Gobierno. Los trabajadores y los sindicatos también fueron muy afectadas por las medidas económicas y sociales adoptadas por el gobierno de Fujimori como la privatización, despidos de servidores públicos, contratos de trabajo flexibles y restricciones en la capacidad colectiva de los sindicatos.

La Organización de los Estados Americanos inició una negociación con el Congreso de la República para discutir la transición e invitó pro forma solo a un representante de la CGTP. La OEA tenía su plataforma política para el período de transición que era la nominación de un gobierno de emergencia nacional, la convocatoria de nuevas elecciones nacionales y regionales, el castigo para los funcionarios públicos corruptos y la adopción de una nueva estrategia económica con prioridad para el empleo y la recuperación del poder adquisitivo. En 2001 se creó el Consejo Nacional de Trabajo y Promoción del Empleo, pero no había mucho entusiasmo debido a la composición del Ministerio de Transición. Además, de los ministros de economía neoliberal, el nuevo ministro de Trabajo provenía de una asociación empresarial y había mostrado mucha simpatía con las leyes laborales creadas por Fujimori.

\section{La transición del apartheid a la democracia en Sudáfrica}

Sudáfrica es actualmente el país más desarrollado de África, además de tener la economía más grande. Fue colonizada en el pasado por holandeses e ingleses, y estos últimos se convirtieron en la fuerza hege- 
mónica en el país, aunque la cultura holandesa africander sigue siendo fuerte; incluso a través de una de las doce lenguas oficiales, el afrikáans -un holandés arcaico-.

Aunque la población negra siempre ha sido mayoritaria, la segregación entre negros y blancos data del siglo XIX y se profundizó gracias a una serie de leyes, decretos y otros mecanismos jurídicos aprobados en el siglo siguiente entre 1910 y 1963. Estos mecanismos prohibían a los negros poseer la tierra y votar, a la vez que fueron sometidos a confinamiento en determinadas áreas (bantustanes) lejos de los lugares de trabajo. El Gobierno entonces podía incluso transferirlos de lugar en cualquier momento. Los negros no tenían acceso a los servicios públicos, no podían unirse a los sindicatos, y mucho menos hacer huelga; tampoco podían asistir a las mismas instituciones educativas que los blancos.

Algunos autores explican la segregación (apartheid) a partir de las creencias religiosas muy ortodoxas de los africanders, pero el hecho es que este esquema permitió generar mano de obra barata que jugó un papel importante en la minería y la industrialización de África del Sur. Este hecho es determinante, como señala Pereira (2012), debido a que esto permitió las inversiones extranjeras directas en las décadas de 1950 a 1960.

La primera organización política creada por los negros sudafricanos fue el Congreso Nacional Africano (CNA) en 1912. En 1921 se fundó el Partido Comunista Sudafricano (PCSA), aunque en el principio sus miembros eran en su mayoría blancos. El CNA adoptó en 1940 una estrategia de resistencia no violenta y se añade a esta estrategia la formulación de la Carta de la Libertad, firmada también por las organizaciones de indios, mulatos, liberales y socialistas. Este documento, que denunciaba el apartheid, apelaba por la abolición de este régimen, a la vez que predicaba la igualdad entre los sudafricanos y la división de la riqueza nacional. La Carta de Libertad se convirtió en el principal programa y referente de la lucha, aunque algunos militantes más jóvenes del CNA comenzaron a discutir la posibilidad de promover acciones más agresivas para enfrentar al régimen. 
Por otro lado, otros sectores del movimiento negro en desacuerdo con el carácter multirracial de la CNA, crearon en 1958 el Congreso PanAfricano (CPA). Dos años más tarde, el CPA realizó una manifestación en la ciudad de Sharpeville en protesta por la ley que limitaba la libertad de movimiento de los negros en las zonas reservadas para los blancos. La policía abrió fuego contra los manifestantes y asesinó a 70 de ellos. Además, el Gobierno puso el CNA, el CPA y el PCSA en la ilegalidad. A raíz de esto, el CNA decidió poner en marcha la resistencia armada a través del Umkhonto we Sizwe (Lanza de la Nación). En 1963 Nelson Mandela y otros líderes de la CNA, acusados de participar en la lucha armada, fueron detenidos y condenados a cadena perpetua.

A pesar de las leyes de confinamiento, comenzó a producirse una cada vez más fuerte afluencia de negros a las ciudades, porque los bantustanes no tenían trabajo y la tierra era casi improductiva. Eso produjo problemas sociales y protestas a la proximidad del blanco. Por ejemplo, la manifestación de estudiantes en Soweto en 1976 en contra de la enseñanza obligatoria del afrikaans, brutalmente reprimida por la policía a un costo de entre 95 (cifra oficial) y 700 muertos (no se conoce la cifra cierta).

La descolonización de los países del Sur de África contribuyó a la interrupción del aislamiento internacional de la CNA, abrió posibilidades para campos de entrenamiento de la "Lanza de la Nación” y abrió el debate sobre un boicot internacional contra Sudáfrica si su gobierno insistía en mantener el régimen del apartheid. Esta campaña antirracista comenzó a crecer mucho en Europa y Estados Unidos, aunque el gobierno de este último en realidad nunca llegó a unirse al boicot, a pesar del apoyo de la ONU y de la Comunidad Económica Europea.

Con la caída de los precios de los minerales en el mercado internacional y el creciente aislamiento del país la situación en los años ochenta fue difícil para los gobernantes blancos de Sudáfrica; las demostraciones internas contra el régimen también se multiplicaron. Con la caída del 
muro de Berlín también desapareció la justificación del anticomunismo para reprimir a la comunidad civil y a sus organizaciones. Así, el gobierno blanco comenzó a negociar con el CNA a través de Nelson Mandela quien con sus compañeros había sido transferido del trabajo forzoso en la inhóspita isla de Robben a una prisión en el continente para facilitar los contactos. En 1990 se llegó a un acuerdo para normalizar la vida política del país.

Las primeras medidas concertadas fueron la abolición de la segregación racial en los lugares públicos, la liberación de los presos políticos, la abolición de los bantustanes y el establecimiento de una constitución provisional que creó una Asamblea Nacional de 400 miembros y un Senado de 90, a la vez que estableció el derecho universal al voto. El presidente sería elegido por la Asamblea Nacional y una nueva división territorial se estableció con nueve provincias del país, cada uno con su propia asamblea legislativa y el gobernador. Se creó entonces una Fuerza Nacional de Paz, con la participación de miembros de las fuerzas armadas y de la guerrilla del ANC. Las primeras elecciones multirraciales en Sudáfrica se llevaron a cabo entre el 26 y 29 de abril de 1994 con la participación de $84 \%$ de los votantes; el ANC ganó con $63 \%$ de los votos, y así fue como Nelson Mandela alcanzó la presidencia.

Los primeros sindicatos que conocemos en Sudáfrica datan de principios del siglo XX, básicamente compuestos por trabajadores blancos. El Congreso de Sindicatos de Sudáfrica (Cosatu) ${ }^{8}$, identificado políticamente con el PCSA y el CNA y con representación multirracial, fue fundado en 1985; es la mayor central sindical del país, con fuertes raíces en el sector industrial y minero. En la campaña electoral de 1994,

$8 \quad$ Hay otras dos centrales sindicales: el Nactu ligada a la CPA y la Fedusa, las cuales provienen de los sindicatos de funcionarios públicos que durante el apartheid eran todos blancos. 
y durante el período de gobierno de Mandela, se formó una alianza tripartita con el PCSA y el CNA, lo que llevó a algunos de sus líderes a la participación del ministerio, mientras que otros fueron elegidos parlamentarios.

En los primeros años de la presidencia de Mandela hubo una serie de medidas para mejorar las relaciones laborales y permitir la participación de los sindicatos en las discusiones sobre las leyes y medidas a adoptar por el Parlamento. Los Convenios 87 y 98 fueron ratificados y establecida la plena libertad sindical, derecho de huelga y la organización en el lugar de trabajo. Fue creado el Consejo Nacional de Desarrollo Económico y Trabajo (Nedlac, por su siglas en inglés), un organismo cuatripartito -gobierno, sindicatos, empresarios y representantes del tercer sector- para discutir y posicionarse sobre las propuestas del Gobierno antes de su envío al Parlamento.

Actualmente hay una gran controversia dentro de la Cosatu en relación al mantenimiento de la alianza tripartita, ya que varios sindicatos consideran que el actual presidente Jacob Zuma no cambió la dirección neoliberal de la economía que se habrían implementado por su predecesor, Thabo Mbeki. Esto permite señalar que el principal reto para el sindicalismo sudafricano es la lucha contra el desempleo que afecta principalmente a los negros, así como conquistar la paridad salarial entre negros y blancos, ya que estos ganan, en promedio, diez veces más que los primeros.

Con respecto a violaciones de los Derechos Humanos durante el apartheid, una Comisión de la Verdad y Reconciliación, presidida por el arzobispo Desmond Tutu, comenzó a funcionar en 1995. El objetivo era analizar lo ocurrido bajo responsabilidad de agentes del Estado y organizaciones de la oposición al apartheid entre 1960 y 1994. La Comisión formó dos comités: uno para evaluar las amnistías y otro para analizar las reparaciones y rehabilitaciones. Los primeros informes resultado de estas comisiones fueron entregados en 1998. 
No existen datos precisos sobre el número de violaciones de los Derechos Humanos, en particular de los más graves. Sin embargo, la Comisión escuchó a 21.519 víctimas y testigos, cerca de dos mil en audiencias públicas; y se registró la denuncia de más de 30 mil violaciones. También se encontró que muchos documentos de propiedad de las fuerzas de seguridad fueron destruidos entre 1990 y 1994 . La Comisión también tenía el poder para poner en práctica un programa de protección de testigos y un centenar de personas se beneficiaron, principalmente los que testificaron en contra de los oficiales de alto rango de la policía. Es importante aquí señalar que para que un acusado de violaciones de Derechos Humanos fuese amnistiado este tenía que proporcionar toda la información acerca de su participación, y recibiría amnistía si el caso llegaba a las audiencias públicas. Se hicieron más de seis mil solicitudes de amnistía, pero el Comité ha concedido solo 849 y rechazó otras 5.392. Los que no fueron amnistiados podían ser procesados, pero no hubo mayor esfuerzo para que esto sucediera.

En cuanto al Comité de Reparaciones y Rehabilitación debe decirse que este era el encargado de hacer recomendaciones al Gobierno en cuanto a los que tenían derecho a alguna reparación o rehabilitación. También aconsejaba en relación a los valores monetarios, ya que es difícil asignar un precio para compensar una violación de los Derechos Humanos. Pereira (2012) anota que hubo varias recomendaciones al respecto, pero pocas fueron cumplidas plenamente por el Gobierno. En relación al tema sindical debe decirse que el movimiento sindical apoyó la labor de la Comisión, aunque no formó parte de ella.

Todavía queda mucho para que Sudáfrica se convierta en un país justo y equitativo, pero no hay duda de que el movimiento sindical jugó un papel importante en el desmantelamiento del apartheid y en la realización de los cambios mencionados anteriormente. 


\section{Conclusiones}

Tras analizar los casos mencionados, se confirma que las transiciones a la democracia se constituyen, en procesos específicos, de maneras singulares y carecen, en la mayoría de los casos como dice Sáez (1992), de garantías mínimamente claras que lleven al éxito de los acuerdos. Sin embargo, a modo de conclusión vamos a hacer algunas comparaciones y comentarios que esperamos puedan servir de reflexión sobre nuevos casos de transición democrática o de negociaciones que tengas como objetivo el final de conflictos.

Lo que se percibe desde el punto de vista económico y social en todos los casos analizados es la transición del conflicto o de la dictadura hacia la democracia y la paz; pero también se percibe, de manera constante, la permanencia de regímenes neoliberales. Lo que demuestra esto es que en los procesos analizados no ha habido suficiente fuerza política y consenso para que los acuerdos en realidad puedan generar cambios concretos y profundos; cambios que vayan más allá de la paz y la democracia. Y se puede señalar que un aspecto que debe ser fortalecido en futuros acuerdos e implementación de los mismos es que debe existir un mayor y determinante marco de garantías. Solo se pudo ver algunos cambios en este sentido cuando los partidos de izquierda se involucraron en las transiciones, como fue el caso de Argentina, Brasil, El Salvador, Nicaragua y Uruguay donde aquellos asumieron el Gobierno. En ese mismo sentido, ha de decirse que los cambios resultaron útiles para elegir a los gobiernos de izquierda en el curso de las transiciones políticas en Sudáfrica y Chile. Sin embargo, obviamente era necesario superar las transiciones hacia la paz y la democracia para tener alguna expectativa de cambios políticos.

Se percibe en los casos estudiados que el movimiento sindical tuvo un papel importante para impulsar las negociaciones de paz y los acuerdos de transición democrática a través de sus movilizaciones y cabildeo para este propósito. Así fue en Sudáfrica, El Salvador, Nicaragua, Brasil, 
Chile, Perú y Uruguay. Sin embargo, solo en Perú hubo participación directa de los representantes sindicales en la negociación de las disposiciones transitorias. En el seguimiento de la aplicación del acuerdo hubo participación del movimiento sindical en todos los países estudiados.

En los diversos aspectos que involucran las violaciones de Derechos Humanos durante los conflictos internos, las dictaduras y en los regímenes autocráticos, como Sudáfrica y Perú, hubo diferentes situaciones. En otros países hubo amnistía con el fin de proteger a los agentes estatales de acusaciones después de la transición democrática. Solo en Sudáfrica la amnistía para violadores de los Derechos Humanos depende de la plena cooperación de los acusados con las investigaciones y el dictamen de una delegación específica de la Comisión de la Verdad y Reconciliación. Más recientemente ha habido iniciativas para derogar la amnistía de los delitos de secuestro y desaparición forzada en Argentina, Chile, Perú y Uruguay. En Brasil se intenta utilizar legalmente la doctrina de algunos Tribunales de Justicia que consideran estos crímenes como imprescriptibles y, por lo tanto, no sujetos a amnistía.

Las Comisiones de la Verdad se han aplicado sobre todo en los procesos de transición, aunque a menudo con el mandato temporal más allá de ellos, como en Sudáfrica, Argentina, Chile, El Salvador, Guatemala y Perú. En Brasil y Uruguay las comisiones se instalaron años después del fin de las dictaduras. Igual, en todos los casos, se observa que la demanda por la verdad y justicia es real, independientemente de la dimensión de las violaciones de Derechos Humanos. Esta es la mediación que Salomón Lerner mencionó en el caso de Perú, aunque en la mayoría de los países los castigos fueran limitados debido a las leyes de amnistía. Sin embargo, es imposible pensar en la reconciliación si las amnistías son amplias, generales y sin restricciones. Del mismo modo, la compensación por violaciones -como fue implementado en Brasilno son suficientes para considerar cerrado el tema. Más razonable es la posición de Sudáfrica, donde la Comisión de la Verdad arbitra las amnistías y la compensación en la escala de violaciones. 
Aunque los acuerdos de paz se han sostenido, una pregunta crucial es en qué medida el proceso de transición ayudó a establecer una cultura de paz, considerando que en Sudáfrica y en la mayoría de los países de América Latina como Brasil, El Salvador, Guatemala, Nicaragua y Perú la violencia política fue reemplazada por altos niveles de delincuencia común. Sin embargo, los indicadores actuales muestran que la mayoría de las personas consideran la democracia como mejor que las dictaduras y, como se mencionó anteriormente, el fin del terror político es un alivio, y en muchos de los países actualmente existe la convicción de que no es aceptable matar para defender posiciones políticas.

La lección más importante para el movimiento obrero que quiere centrarse en procesos similares a los estudiados es, en primer lugar, la de tener una plataforma para el acuerdo de paz y la transición. Esto debe incluir los cambios políticos y las herramientas necesarias para ampliar la participación popular en las decisiones y, por supuesto, no habrá acuerdo si los beligerantes no se incorporan a la vida política normal. En segundo lugar, es necesario revisar lo que pasó durante el conflicto o la dictadura y para eso sirven las Comisiones de la Verdad que tienen ciertas reglas a seguir, tales como su composición, duración, estructura y mandato. Del mismo modo que nadie depone sus armas si no hay amnistía, tampoco habrá reconciliación si no hay justicia para todos los que se levantaron en armas.

Por último, la plataforma debe incluir una propuesta viable de los temas que pueden cambiar económicamente y socialmente en el proceso, pero eso también depende de la correlación de fuerzas, la representatividad y la capacidad de organización del movimiento sindical. 


\section{Referencias bibliográficas}

Burt, Jo-M. (2009). "Guilty as charged: The trial of former Peruvian president Alberto Fujimori for human rights violations”. En The International Journal of Transitional Justice. 3. (3). Inglaterra: Oxford Journals, 2009. 385- 405.

Enciclopédia do Mundo Contemporâneo (2000). São Paulo: Publifolha.

Grandin, G. (2002). A revolução guatemalteca. São Paulo: Editora UNESP.

Montgomery, T. y Wade, C. (2002) A revolução salvadorenha. São Paulo: Editora UNESP.

Pereira, A. D. (2012). A revolução sul-africana. São Paulo: Editora UNESP.

Sáez, M. (1992) "Las transiciones a la democracia en España, América Latina y Europa Oriental. Elementos de aproximación a un estudio comparativo”. En Cuadernos de CAPEL. 35, IIDH-CAPEL. San Jose da Costa Rica.

Zimmermann, M. (2002). A revolução nicaraguense. São Paulo: Editora UNESP.

\section{Otras fuentes}

Entrevistas: con Amanda Villatoro (El Salvador), Marita Gonzalez e Andres Larosgoytia (República Argentina).

Normativa: Decretos relativos a la creación de las Comisiones de la Verdad en Argentina, Brasil, Chile, El Salvador, Guatemala, Perú, Sudáfrica e Uruguay.

Larraín, P. (Dir.). (2012). “NO” [cinta cinematográfica]. Chile: Fábula Productores.

Sitio: www.pitcnt.org.uy 